\title{
Albin T. Jousse, Medallist of the International Medical Society of Paraplegia - A Profile
}

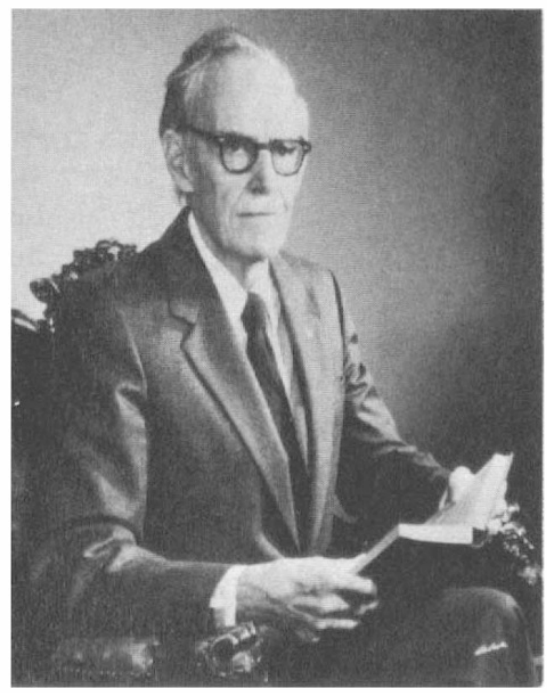

The year was 1945 and World War II was grinding to an end in Europe. At last the Department of Veterans' Affairs of Canada was stirring and decided to undertake in Toronto the development of a rehabilitation programme for spinal cord injuryveterans. The objective was to enable them to live at home, independent of hospital care and to be gainfully employed. The programme for central Canada was to be located at Lyndhurst Lodge, a branch of Christie Veterans Hospital in Toronto.

The paramount need was for a physician who would develop the rehabilitation programme and provide dedicated knowledgeable medical care for these patients over the long pull. In wartime Canada no such physician, now identified as a paraplegist, existed. By the greatest of good fortune for hundreds of patients, veterans and civilians, the late Professor K. G. McKenzie, Canada's first neurosurgeon, identified Dr Jousse as the ideal man for the job, knowing well that he had no formal training in rehabilitation medicine.

An Honours Graduate of the Faculty of Arts of McMaster University and of Medicine at the University of Toronto, he financed his education independently by practising optometry part time. He entered McMaster some 7 years after he had become a qualified optometrist. Following graduation from the University of Toronto, he became fully trained and qualified in internal medicine with additional experience in psychiatry. During World War II he taught surgical neurology to medical students as a clinical assistant to Dr McKenzie. Dr Jousse was about to leave Toronto to serve as a medical consultant in a clinic in northern Ontario. His response to being offered the post of Medical Director, which did not yet officially exist of a programme which had not been established, was on immediate unequivocalacceptance. He felt that his war effort had been inadequate. No escape is possible from recording that Dr Jousse when a medical student discovered he suffered from syringomyelia and in the intervening years had developed severe limitations of mobility which have been progressive.

Under Dr Jousse's superb leadership at Lyndhurst, there developed a great team of physiotherapists, physical training instructor, medical orderlies, vocational counsellor and above all, nurses. They quickly came to share Dr Jousse's 
commitment to the care of these individuals with spinal cord injury. Later, Dr Jousse was joined by Dr William Geisler.

The physical programme of rehabilitation was based on the work of $\mathrm{Dr}$ Donald Munro of the Boston City Hospital and Dr George Deaver at the New York Institute for the Crippled and Disabled. Dr Deaver and his staff provided a period of intensive training for Dr Jousse and two Lyndhurst physiotherapists. This was a major contribution for Dr Jousse in 1945 was without training in the physical rehabilitation techniques available for paraplegics and quadriplegics.

From this small beginning, led by Dr Jousse, the veterans transformed Lyndhurst Lodge; there developed an active, strenuous, physically demanding programme. Walking with long leg braces and crutches was accomplished by most of the veterans with paraplegia and independent wheelchair life became the norm.

On-the-job training and education were undertaken in the community in the appropriate factory, shop or institution. There were no machine shops or the like at Lyndhurst. Dr Jousse's design was to accustom the patient to life and work in the community. This proved to be a most valuable policy. At first the decline of an offer to install shops at Lyndhurst was ill received.

The success of Dr Jousse's overall programme can be guaged by the fact that $90 \%$ of patients admitted to Lyndhurst have been discharged to their homes; of that $90 \%$ approximately half became gainfully employed, pursued further education, or undertook technical training. Dr Jousse's support, infinite patience, human understanding and care of the individual SCI patient was a key influence motivating the individual to strive for and achieve independence.

With the success of the programme came significant clinical research, based on some 2000 patients, veterans and later civilians, with a successful follow-up of $98 \%$. Examples are the long term actuarial study carried out with Dr Geisler and Dr Breithaupt of the Manufacturer's Life Insurance Company, leading to actuarial tables regarding life expectancy of SCI patients. Neurological studies with Dr Henry Barnett led to the identification of progressive 'Myelopathy as a Sequel to Traumatic Paraplegia'.

Later in his career, Dr Jousse served as Director of the School of Physical and Occupational Therapy (renamed as the School of Rehabilitation Therapy) at the University of Toronto. He was a Professor of Physical Medicine and Rehabilitation. He was a founding member of the Province of Ontario Human Rights Commission, providing a strong voice for the protection of the disabled.

The Government of Canada in recognition of his compassionate devotion, unflagging care, and contributions to the understanding of spinal cord injury patients has bestowed upon him its highest honour: The Order of Canada. The patients have made him their beloved physician.

Dr E. R. Botterell Kingston, Ontario, Canada 